\title{
Strategies for pollen harvest and storage for increasing pollination and yield in hybrid rice seed production of Mestiso 19 cultivar
}

\author{
Susan R. Brena ${ }^{1 *}$, Alpha Grace S. Ferriol ${ }^{1}$, Richie Eve Ragas ${ }^{2}$ and Jennifer M. Manangkil ${ }^{3}$
}

\author{
${ }^{1}$ Seed Technology Unit, Genetic Resources Division, PhilRice Maligaya Science City of Munoz, Philippines. \\ 2Biological Science Cluster, University of the Philippines Cebu, Gorordo St., Lahug, Cebu City, 6000, Philippines. \\ ${ }^{3}$ Department of Biological Sciences, College of Arts and Sciences, Central Luzon State University, 3119,
}

Nueva Ecija, Philippines.

*Corresponding author. Email: sr.brena@philrice.gov.ph

Copyright (C 2019 Ragas et al. This article remains permanently open access under the terms of the Creative Commons Attribution License 4.0, which permits unrestricted use, distribution, and reproduction in any medium, provided the original work is properly cited.

Received 29th November, 2018; Accepted 26th January, 2019

\begin{abstract}
Attainment of high seed yield in hybrid rice seed production is a function of the amount of pollen that the male parent can shed during pollination. Low pollen load of the male parent (TG101M) of hybrid rice, Mestiso 19 leads to low seed yield which limits the number of hybrid rice seed growers engaged in its hybrid seed production. Artificial pollination, through collection and storage of sufficient amount of pollen may provide a solution to the problem. Additional pollen artificially loaded onto stigmas of female parent of Mestiso 19 (PRUPTG101) may increase seed yield. The study was conducted during wet and dry season of year 2016 and 2017 at Phil Rice Central Experiment Station to develop technique in pollen collection and storage of TG101M. Pollens were collected at anthesis, 30 minutes and 1 hour after anthesis, then stored in amber glass, paper and ziplock plastics and stored for 24,48 and 72 hours in $28^{\circ} \mathrm{C}, 5^{\circ} \mathrm{C},-5^{\circ} \mathrm{C}$. Pollens were grown in three different media for pollen viability and germination and viewed under the microscope for pollen tube growth. Pollen viability and germination was high at anthesis and decreased thereafter. Pollen grains grown in media 2 maintained pollen viability even after 1 hour after anthesis. Pollen germination decreased over time regardless of media used. Pollen tube length was consistently high at anthesis when pollen grains were grown in media 2 and 3 only. The length of pollen tube growth from medium 2 differed between $30 \mathrm{~min}$ and 1 hour. Less than $50 \%$ viable pollen was achieved after 24 hours of storage. Pollen viability and germination decreased beyond 24 hours. To increase the viability of collected pollen from TG101M for possible artificial pollination, grains must be collected at anthesis and stored immediately in amber glass under cold storage at negative $5^{\circ} \mathrm{C}$.
\end{abstract}

Keywords: Hybrid, pollen collection, pollen storage, pollen viability, pollen germination, pollen tube growth.

\section{INTRODUCTION}

Yield advantage of hybrids over inbreds has led to increase demands of hybrid seeds. Consequently, this prompted the necessity of increasing hybrid seed supply. Mestiso 19 (NSIC Rc202H) is one of the two-line publicbred rice hybrids that gains popularity across regions of the Philippines due to its high yields (reported national average reached $8 \pm 1$ ton ha $^{-1}$ ). The bottleneck, however, remains in the production of its seeds. Hybrid seeds are produced by cross-pollination between a male-sterile (female) line and a fertile line (male). Since rice is predominantly self-fertile and cross-pollination occurs at a very low rate (Roberts, 1961) securing cross-pollination and consequent fertilization remains a hurdle (Marassi et al. 2006). Source of pollen, particularly viable pollen is proved to be positively correlated to out-crossing rate (Zheng et al., 2018). Insufficient pollination has been found to be one of the most important factors responsible for low yields in many field crops (Shivanna and Sawhney, 1997).

Pollen, the male gametophyte of the flowering rice plant, plays an important role in cross-pollination. Upon landing on the stigma for pollination, the pollen grain produces a long pollen tube to deliver sperm to the ovule for fertilization (Wang and Jiang, 2011). Fast pollen tube elongation is essential for the fertilization of plant ovules, and pollen grains compete for success among those tubes within the styles (Lee et al., 2011). Once germination occurs, pollen tubes must enter the style. Pollen tube growth is an extremely polarized and highly dynamic cellular process, making it an ideal single-cell model system for studying molecular mechanisms of signal transduction, protein trafficking, vesicular secretion and endocytosis in plant cells (Wang and Jiang, 2011; Matsui et al., 1999a;1999b). Pollen adhesion to the stigma depends on the deposition and sedimentation of the pollen to the substratum and on the subsequent formation of attachment bonds. It is likely that components of both cell surfaces are involved in the contact and attachment steps of the adhesion process (Matsui et al., 1999a). The viability, tube growth and morphological homogeneity related to pollen quality are the most important properties in fruit trees. These properties are useful for plant breeders, geneticists, and growers (Bolat and Pirlak, 1999).

Artificial pollination provides a solution to this problem. One method of artificial pollination is pollen supplementation, which requires the collection of sufficient amounts of pollen and the storage of viable pollen for short (hours to weeks) or long (months to years) periods. Methods for pollen collection has been developed for many species of interest and revealed the critical importance for increased longevity by using high quality pollen, desiccating it sufficiently in a rapid manner, and subsequently storing it at very low temperatures (Connor and Towill, 1993; Dafni and Firmage, 2000; Firmage and Dafni 2001). Because pollen shed immediately after 
anthesis, short duration (10 or $20 \mathrm{~min}$ ) treatments of pollen at different conditions are important for evaluation. In flowering fescue, for examples, when fresh pollen was germinated at different temperatures, germination was reduced only at $40^{\circ} \mathrm{C}$, a result similar to that in sorghum (Tuinstra and Wedel, 2000). When pollen was stored for 10 or $20 \mathrm{~min}$, its viability was not significantly changed at 18 to $32^{\circ} \mathrm{C}$, but viability was reduced when temperature was at or above $38^{\circ} \mathrm{C}$. These results indicated that pollen viability was not influenced over the range of temperatures often encountered during the pollination season, while excessively high temperatures during this period may negatively influence pollen viability.

Storage of pollen at low temperatures with good results has been attempted in a number of plant species, such as dogwood, protea, mango, and almond (Craddock et al., 2000, Van Der Walt and Littlejohn, 1996, Dutta et al., 2013; Martínez-Gómez and Gradziel, 2002). Long-term storage of pollen is useful to conserve the gene pool and to overcome temporal and spatial isolation of the parent species in breeding programs. A method for pollen collection from freshly dehiscing anthers of litchi using cyclohexane has been reported by Chaudhury et al. (2010). In addition, cryopreservation (in liquid nitrogen) has been successfully applied to achieve long-term pollen storage over periods of up to four years. However, such methods require very sophisticated laboratory equipment. Obtaining accurate pollen viability rates may depend strongly on storage conditions, protocols used and other factors. Pollen viability is generally considered to indicate the ability of the pollen grain to perform its function of delivering the sperm cells to the embryo sac following compatible pollination (Shivanna et al., 1991).

Pollen viability of $O$. sativa, $O$ rufifugon and its hybrids could last for 60 to $70 \mathrm{~min}$. The hybrids had the lowest pollen germination rate (approximately 34\%) and medium pollen longevity. More than $50 \%$ of the pollen grains were viable after $10 \mathrm{~min}$ and a few were still viable after $40 \mathrm{~min}$ (Song et al., 2001). Chen et al. (2008) reported that rice pollen grains germinate at 2 min after pollination and the pollen tube penetrated stigma into style in 5 to $10 \mathrm{~min}, 30$ min later the end of pollen tube reached the bottom of ovary, and only some pollen tubes arrived at embryo sac at $40 \mathrm{~min}$ after pollination. Saoji and Rewatkar (2015) successfully collected pollen of $O$. sativa from 9 to $11 \mathrm{am}$, then stored in a room temperature and $3^{\circ} \mathrm{C}$ in refrigerator with $\mathrm{RH}$ level of $0,10,20,30,40,60,80$, and $100 \%$. In the study of Ramesh et al. (2017) on 14 inbred and 7 hybrid rice cultivars, it was discovered that IR-64 and PHB-71 were recorded to have maximum and minimum pollen viability under ambient temperature while PHB-71 and PA6444 recorded the maximum and minimum pollen viability under elevated temperature stress respectively.

Pollen collection and storage will allow for wide hybridization across seasonal and geographical limitations. With adequate pollen available, additional pollen can be artificially loaded onto stigmas to increase pollination and yield. This eliminates the need to coordinate the timing of the sexual maturity of two plants and effectively eliminate one of the time factors in the plant breeding process such as when pollen shed does not coincide with receptor maturity. Furthermore, the longterm storage of viable pollen provides a unique ability to conserve and manipulate genetic resources. The ability to retrieve viable pollen, obtained from a group of individual plants stored for long periods of time provides great flexibility in plant breeding programs. This study aims to develop a simple procedure for pollen collection and storage to increase seed yield in hybrid rice seed production in Mestiso 19.

\section{METHODOLOGY}

\section{Biological material}

Parent rice lines, PRUPTG101 (female parent) and
TG101M (male parent) of hybrid rice Mestizo 19 (NSIC $\mathrm{Rc} 202 \mathrm{H}$ ) were used in SxP (Sterile parent and Pollen parent) experimental seed production. Field experiments were conducted under irrigated condition during the dry and wet season at the Philippine Rice Research Institute (PhilRice) Central Experiment Station, Maligaya, Science City of Muñoz, Nueva Ecija, Philippines. Solar radiation was measured using a Gunn-Bellani radiation-integrator (Baird \& Tatlock, London, UK).

\section{Pollen collection time and media for pollen growth}

Pollen should be harvested soon after anthesis, usually in the morning hours (Ganeshan et al., 2008; Towill 2004). Shelf life is short for pollen collected from immature, aged, or weather-damaged anthers (Towill 1985). It is usually more practical to collect anthers in the field and then separate the pollen grains from the anthers in a laboratory environment soon after collection. All pollen must be processed immediately (within hours) to ensure maximum potential longevity.

During the rice anthesis, a mature tiller that is actively flowering was bagged using paper sack and was shaken to release as much pollen. Rice pollen grains were collected daily at anthesis, $30 \mathrm{~min}$ and 1 hour after anthesis for three days by shaking the rice panicles contained inside the paper bag. Collected pollens were air dried at room temperature and sifted using a mesh size of $0.125 \mathrm{~mm}$ to remove anthers and contaminants. Pollen grains collected daily were grown immediately in three different media for pollen viability, germination, and pollen tube growth. Portion of the collected grains were stored for 1 hour under ambient condition $\left(28^{\circ} \mathrm{C}\right)$ before growing in the three media and the same parameters were observed.

The composition of each culture medium is listed in Table 1. Culture media composition were freshly prepared and modified from (Dai et al., 2007 and Coast et al., 2014) pollen grains were considered germinated when the pollen tube length is equal or greater than the diameter of the pollen grain (Dafni and Firmage, 2000). To assess the extent of pollination and tube growth, rice flowers were emasculated and artificially pollinated by hand (before fixing). The samples were fixed in a solution (3:1 ethanol:acetic acid) and were stored at $4^{\circ} \mathrm{C}$ in $70 \%$ ethanol until use. The dissected pistils and ovaries were washed twice with distilled water and then incubated in a solution of $8 \mathrm{~N} \mathrm{NaOH}$ for 1 hour. Then, the samples were stained in $0.1 \%$ aniline blue in $\mathrm{K}_{3} \mathrm{PO}_{4}$ buffer and examined under UV illumination to visualize the callose of pollen tube. Germinated pollen refers to pollen grains attached to the stigma whose pollen tube growth can be detected by UV fluorescence. The numbers of pollen tubes and the extent of their growth through the length of the style were assessed. Boric acid, calcium nitrate and sucrose concentrations in the medium might have to be optimized according to species (Bolat and Pirlak 1999; HeslopHarrison 1992). The hanging-drop method involves the placement of a slide or coverslip with liquid medium and pollen inverted over a $100 \%$ humidity chamber (Rajasekharan and Ganeshan 1994). For observation, the slide is returned to an upright position and observed under a microscope. Rice anthers or pollen grains can be desiccated using silica gel at room temperature (Marassi et al., 2006)

\section{Pollen storage materials, conditions and durations}

In the succeeding experiment, pollen grains were collected only during anthesis. The collected pollen grains were separated using a small camel hairbrush. Then, the pollen grains were divided into two for in vitro germination testing and the remaining half for storage. All samples for in vitro germination and storage were replicated thrice. Storage containers used were amber glass, paper envelope and zip lock plastic and then stored in different storage 
Table 1. List of media used for pollen viability test with their components and individual concentrations.

\begin{tabular}{lcccc}
\hline Culture Medium & \multicolumn{4}{c}{ Compositions } \\
\hline 1 & $10 \% \mathrm{PEG}$ & $20 \%$ Sucrose & $0.05 \% \mathrm{CaCl}_{2}$ & $0.01 \%$ Boric acid \\
2 & $3 \% \mathrm{Ca}\left(\mathrm{NO}_{3}\right)_{2}$ & $5 \%$ Sucrose & $1 \% \mathrm{Agarose}$ & $10 \%$ Boric acid \\
3 & $4 \%$ Calcium nitrate & $14 \%$ Sucrose & $1 \%$ Potassium Nitrate & $1 \%$ Boric acid \\
\hline
\end{tabular}

Table 2. Treatment conditions, packaging containers and time of storage used for pollen banking.

\begin{tabular}{lcc}
\hline Storage containers & Storage Temperature & Duration of Storage \\
\hline Amber glass & Room Temp & 24 \\
Paper envelope & $5^{\circ} \mathrm{C}$ & 48 \\
Zip lock & $-5^{\circ} \mathrm{C}$ & 72 \\
\hline
\end{tabular}

temperatures and durations, $-5,5$ and $28^{\circ} \mathrm{C}$, for 24,48 and 72 hours (Table 2). The in vitro germination test was performed using a culture medium containing $1 \mathrm{mg} \mathrm{H}_{3} \mathrm{BO}_{3}$, $3 \mathrm{mg} \mathrm{Ca}\left(\mathrm{NO}_{3}\right)_{2}, 1.7 \mathrm{~g}$ sucrose, and $0.07 \mathrm{~g}$ agarose in 10 $\mathrm{mL}$ sterile distilled water (Rodriguez-Enriquez et al. 2013) and was incubated at room temperature in a humid chamber. After 2 to 3 hours, pollen grains were stained with $0.005 \%$ aniline blue solution $[0.005 \%$ aniline blue in $0.15 \mathrm{M} \mathrm{K}_{2} \mathrm{HPO}_{4} \quad(\mathrm{pH}$ 8.6)] and counted under a fluorescence microscope. Twenty different fields of vision, each with at least 30 grains were examined per treatment.

\section{Statistical analysis}

Data were analyzed and compared following two-way randomized complete block design analysis of variance (STAR, Statistical Tool for Agricultural Research) at $(p<0.05)$ level and means were compared based on the least significant difference test (LSD).

\section{RESULTS AND DISCUSSION}

\section{Collection time and culture media}

From the field experiments of Sterile Parent and Pollen Parent (SxP) seed production of Mestiso 19, pollen parents were observed as soon as the rice florets dehisce from 9:45 to $10: 00$ in the morning and until $12: 30$ to $1: 00$ in the afternoon. Spikelets of TG101M were collected soon during the anthesis i.e. between 9 to $11 \mathrm{am}$. Soon after collection, pollens were grown in the laboratory for viability and germination testing (Figure 1). Results showed that regardless of media used, highest percentage pollen viability was achieved from grains collected at anthesis (Table 3 ). Pollen grains collected $30 \mathrm{~min}$ after anthesis had lower pollen viability than those collected after anthesis and 1 hour after anthesis (Table 3). Pollen grain collection was usually done soon after anthesis, usually in the morning hours (Ganeshan et al., 2008; Towill 2004). Volk (2011) suggested that all pollen should be collected from the field and must be processed immediately to guarantee its utmost potential longevity. Constant high percentage pollen viability $(>50 \%)$ was observed from grains grown in culture medium 1, even after 30 mins and 1 hour of collection (Table 3) The same observation was noted in percentage pollen germination. Regardless of collection time, pollen grains grown in medium 1 had the highest pollen viability followed by medium 3 , and lastly by those grown in medium 2. Percent pollen germination was highest after pollen grains were collected 30 minutes after anthesis then grown in medium 1 . It was noted that pollen grains collected 30 mins after anthesis had $35.58 \%$ germinated pollen which was $1.16 \%$ higher than those collected after 1 hour (34.42\%) and $12.85 \%$ higher than pollens collected during the anthesis. Significant difference was observed in percent pollen germination between pollen grains collected at anthesis and $30 \mathrm{~min}$ after anthesis (Table 3). Results showed that pollen tube length was consistently high in pollen grains collected at anthesis. Comparison of different media revealed that pollen grains grown in medium 1 obtained the longest pollen tube length. Evaluation of collection time showed that grains collected after 30 mins and 1 hour obtained the longest pollen tube growth measuring $0.16 \mathrm{~mm}$ (Figure 3 ). The $52 \%$ pollen viability recorded in this study was comparable to the highest percent pollen $(60 \%)$ viability reported previously for in vitro research on pollen $O$. rufipogon (Song et al., 2001).

In vitro germination in culture medium is a technique that simulates the conditions of the style-stigma, inducing germination and pollen tube growth. Culture medium 1 which consisted of $10 \%$ PEG, $20 \%$ sucrose, $0.05 \% \mathrm{CaCl}_{2}$ and of $10 \%$ PEG, $20 \%$ sucrose, $0.05 \% \mathrm{CaCl}_{2}$ and $0.01 \%$ boric acid was observed to give the best results in terms of percentage viability, germination and pollen tube length. Maximum pollen growth was observed in rice cultivars CG14 (86\%), IR64 (77\%) and N22 (93\%) grown in culture media with boric acid, calcium nitrate tetrahydrate $\left[\mathrm{Ca}\left(\mathrm{NO}_{3}\right)_{2} .4 \mathrm{H}_{2} \mathrm{O}\right.$ ], PEG $4000,1 \mathrm{~L}$ deionized water at $27^{\circ} \mathrm{C}$ (Coast et al., 2016). Boric acid is crucial for pollen germination and pollen tube growth and is required at concentration of $0.01 \%$ for most species (Boavida and McCormick, 2007). In their study on in vitro germination in Arabidopsis thaliana, they found out that the best culture medium is the one that contain $0.01 \%$ boric acid. The results obtained in this study is supported by the finding of Zhang et al., 2010 that the optimal medium for in vitro germination of rice pollen was the one containing $10 \%$ PEG (molecular weight 4500), $20 \%$ sucrose, $0.05 \%$ $\mathrm{CaCl} 2$, and $0.01 \%$ boric acid at $\mathrm{pH} 5.6$. Besides the carbohydrate source, boron and calcium play important roles in pollen germination and pollen tube growth (Steer and Steer 1989). In the absence of boron and calcium, pollen tubes often show abnormalities such as coiling and swelling of the tip, or they even burst. (Shivanna and Rangaswamy 1992). In addition, Coast et al. (2016) reported that highest pollen germination and tube growth were achieved across diverse rice cultivars by adjusting the concentration of calcium nitrate.

Pairwise comparison of viability and germination means showed that the pollen grains collected during anthesis have the highest mean viability (Table 3 ). Significant differences were observed in pollen viability of pollen grains collected at different times and then grown in culture medium 2. Least percentage viable pollens were observed in medium 2 from pollen grains collected 30 min after anthesis. Analysis of variance showed that media, collection time and its interaction significantly affected pollen viability and germination (Table 4).

\section{Collection time and culture media after one hour storage}

Part of the pollen grains collected then kept for 1 hour 


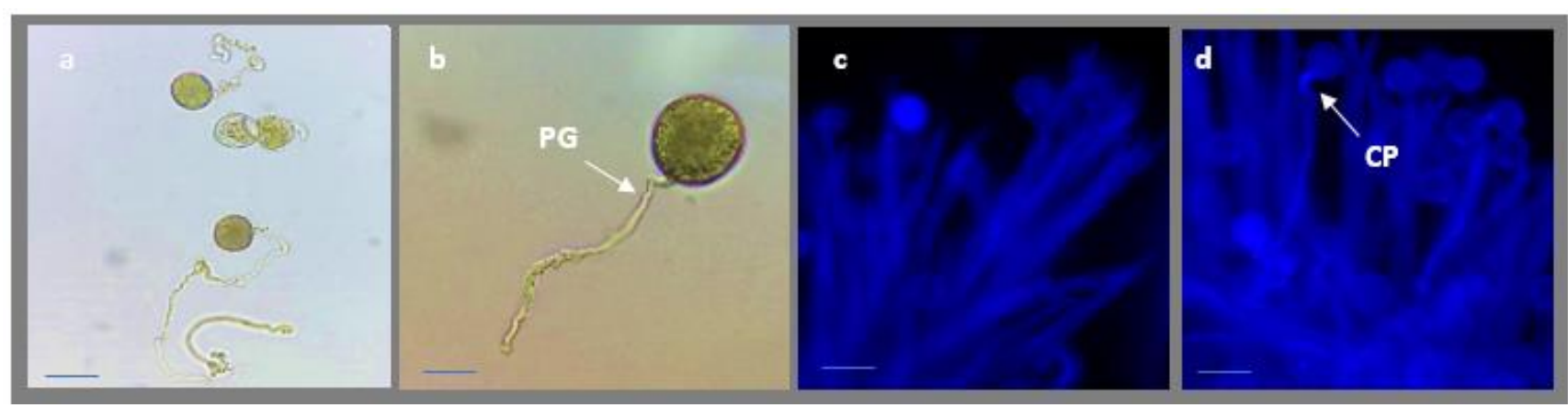

Figure 1. Photographs of pollen tube growth in stigma under florescence microscope. Pollen tube growth of Oryza Sativa TGMS hybrid parental TG101M in vitro. Pollen tubes are shown following $10 \% \mathrm{PEG}, 20 \%$ sucrose, $0.05 \% \mathrm{CaCl}_{2}$ and $0.01 \%$ boric acid at pH 8. (a) A group of clumped pollen grains stained with aniline blue in the prosses of germination. (b) Individual in vitro pollen germination and elongation stained with aniline blue under light showing pollen tube growth. (c) Artificial growing of pollen in the brushy part of stigma (d) Showing pollen tubes callus formation penetrating in stigma brushes stained with DAPI florescence microscope light. Arrows indicate examples of key features: PG, pollen grain; CP, callus plug. Bars, $50 \mu \mathrm{m}$.

Table 3. Percentage pollen viability and germination, and pollen tube length $(\mathrm{mm})$ at indicated treatments.

\begin{tabular}{llcccc}
\hline Variable & Collection time & Medium 1 & Medium 2 & Medium 3 & Means \\
\hline \multirow{4}{*}{ \% Viability } & At Anthesis & 52.39 & $36.55^{\mathrm{a}}$ & 47.25 & $42.61^{\mathrm{a}}$ \\
& After 30 mins & 48.49 & $3.77^{\mathrm{c}}$ & 12.4 & $21.55^{\mathrm{b}}$ \\
& After 1 hour & 50.12 & $20.85^{\mathrm{b}}$ & 38.89 & $39.39^{\mathrm{a}}$ \\
& means & $50.33^{\mathrm{a}}$ & $20.39^{\mathrm{b}}$ & $32.82 \mathrm{~b}$ & \\
& & & & & \\
& At Anthesis & $22.73^{\mathrm{b}}$ & $16.30^{\mathrm{a}}$ & $18.38^{\mathrm{a}}$ & 19.4 \\
& After 30 mins & $35.58^{\mathrm{a}}$ & $1.03^{\mathrm{b}}$ & $3.35^{\mathrm{b}}$ & 13.32 \\
& After 1 hour & $34.42^{\mathrm{a}}$ & $9.58^{\mathrm{ab}}$ & $17.73^{\mathrm{a}}$ & 20.44 \\
& means & 30.91 & 8.97 & 13.15 & \\
& & & & & \\
Pollen Tube Length (mm) & At Anthesis & $0.11^{\mathrm{a}}$ & $0.0733^{\mathrm{b}}$ & $0.0833^{\mathrm{a}}$ & \\
& After 30 mins & $0.16^{\mathrm{a}}$ & $0.04^{\mathrm{b}}$ & $0.0367^{\mathrm{b}}$ & \\
& After 1 hour & $0.1633^{\mathrm{a}}$ & $0.0667^{\mathrm{b}}$ & $0.0867^{\mathrm{b}}$ & \\
\hline
\end{tabular}

*Means in the column with the same letter=ns. Means in rows with the same letter =ns.

Table 4. Analysis of variance of pollen viability, pollen germination and pollen tube growth under varying collection time and culture media used.

\begin{tabular}{lccc}
\hline \multirow{2}{*}{ Source of Variation } & \multicolumn{3}{c}{ Mean Square } \\
\cline { 2 - 4 } & Viability & Germination & Pollen Tube Length \\
\hline Collection time & $1157.53^{*}$ & $132.98^{*}$ & $0.0016^{*}$ \\
Media & $2036.37^{\star}$ & $1221.28^{*}$ & $0.0194^{*}$ \\
Collection time x Media & $325.32 \mathrm{~ns}$ & $205.51^{*}$ & $0.0022^{*}$ \\
CV \% & 39.02 & 32.80 & 24.85 \\
\hline
\end{tabular}

under room temperature resulted in highest percentage pollen viability and germination from pollen grains collected after anthesis (Figure 2A and B). Pollen tubes that elongate to a length that is at least the diameter of the pollen grain are considered viable (Dafni and Firmage 2000). Those collected one hour after anthesis had the least number of viable and germinated pollen. Highest percentage pollen viability and germination were observed in culture medium 3 (Figure $2 \mathrm{~A}$ and B). Pollen viability and germination decreased over time regardless of media used (Figure 2A and B). Pollen viability decreased after anthesis, but pollen grains grown in medium 2 had the highest pollen viability even after 30 minutes and 1 hour pollen collection after anthesis. Regardless of collection time, pollen grown in medium 1 exhibited the longest pollen tube length (Figure $2 \mathrm{C}$ ). Variation in percentage pollen viability, germination, and pollen tube growth were greatly affected by collection time and culture media used (Figure 2).

Highest mean pollen viability was observed from pollen grains collected during anthesis. Pollen viability was influenced by relative humidity, temperature, atmospheric composition and oxygen pressure (Stanley and Linskens, 1974). Pollen tube length was highest when pollen grains were collected at anthesis then grown in culture medium 2. The present study showed that the best time to collect pollen grains was during anthesis because more pollens remained viable as they are not yet exposed for long period to environmental factors like heat and relative humidity. Studies in pollen biology showed that pollen exposed to heat stress and high relative humidity showed poor germination (Shivanna and Rangaswamy, 1992). Water content, cooling rate and storage temperature all affect the longevity of stored pollen (Buitink et al., 1996; 2000). Field conditions and relative humidity at the time of harvest affect the pollen moisture content, and germinability is impaired when pollen is kept for any length of time in wet or high-humidity conditions (Hoekstra 1986). Pollen ages quickly when held at $24^{\circ} \mathrm{C}$ and $75 \%$ relative humidity (RH) (Van Bilsen et al., 1994). Analysis of variance showed that culture media, collection time and media and collection time interaction significantly affected the viability, germination and tube length of pollen (Table $5)$. 

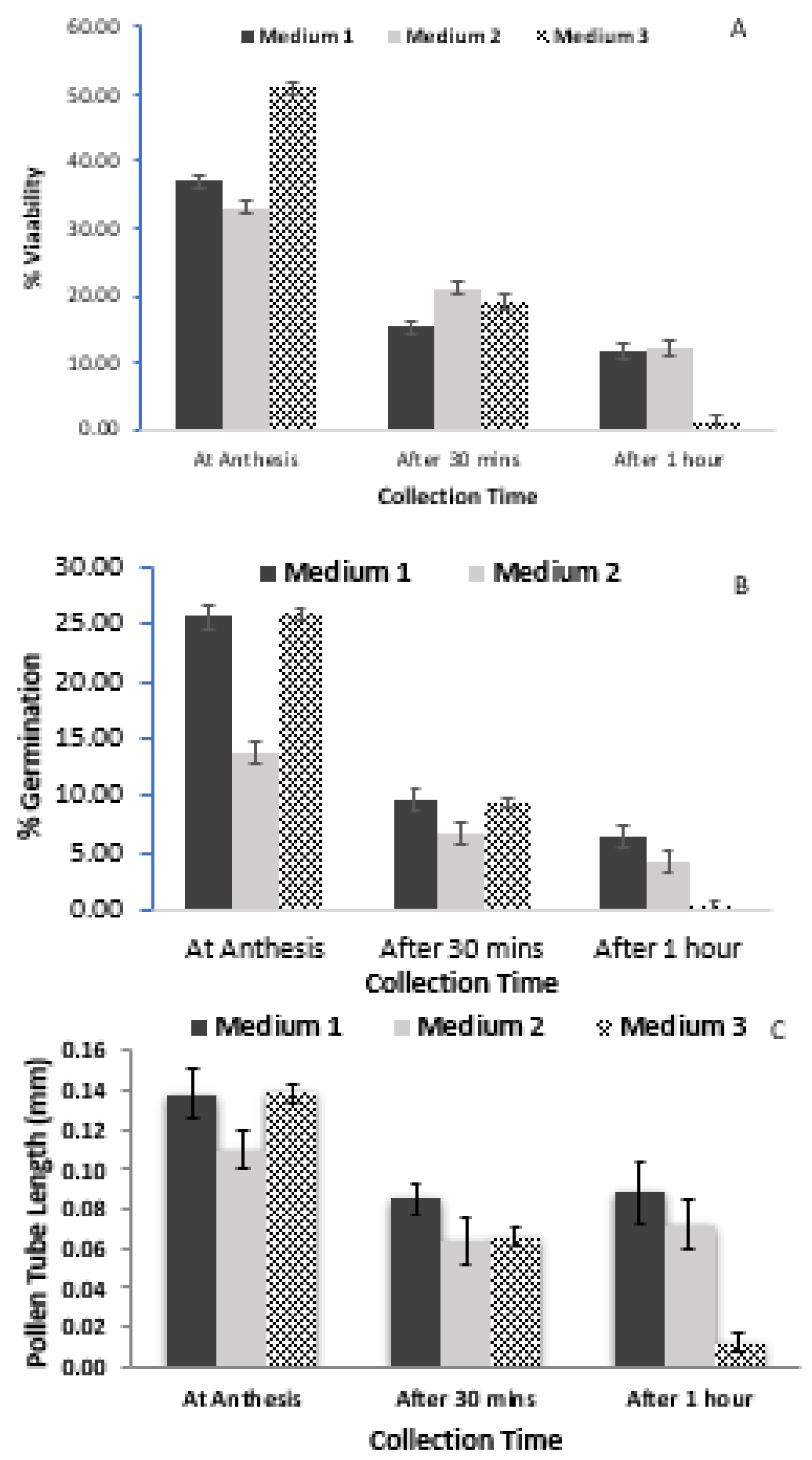

Figure 2. Percent pollen viability $(A)$, germination $(B)$ and pollen tube length (C) at indicated treatments after $1 \mathrm{hr}$ of storage. Each data points represents the average of three replications. Error bars indicated standard error bars $(n=27)$.

\section{Pollen storage materials and conditions}

After anthesis collected anthers of TG101M were stored in ziplock plastic, paper, and amber glass for 24,48 and 72 hours prior to growing pollen grains in vitro. Some pollen grains were grown artificially in the stigma of female parent (PRUP TG101), pollen grains showed successful penetration of pollen tube in the brush part of stigma (Figure 1). Highest pollen viability of less than $50 \%$ was achieved only after 24 hours storage. Number of viable and germinated pollen decreased over time regardless of media used. Regardless of storage duration, pollen stored in amber glass resulted in highest percentage viability and germination (Figure $3 \mathrm{~A}$ ). Temperature is the most important environmental factor affecting plant reproductive processes such as pollen germination, pollen tube growth and seed setting (Kakani et al., 2005). From the early pollen studies, high temperatures ( $>30 \mathrm{C}$ ) inhibited in vivo pollen germination and pollen tube penetration (Suy, 1979 Barrow, 1983).

Regardless of storage temperature and duration high percentage pollen viability and germination was observed in all pollen grains stored in amber glass (Figure $3 \mathrm{~A}$ ). It was noted that pollen grains stored after 24 hours in amber glass at $-5^{\circ} \mathrm{C}$ had the highest percentage of viable $(45 \%)$ and germinated pollen $(<30 \%)$ (Figure 3 ). Lowest percentage pollen viability $(18.3 \%)$ was recorded when pollen was stored in paper at room temperature. Lowest percentage pollen germination was observed in pollen stored in zip lock plastic at room temperature (Figure 3B). Stanley and Linskens (1974) on pollen viability study stated that low humidity during pollen storage usually has a positive effect on pollen viability. Moreover, at low temperatures, pollen remains viable longer in most species analyzed (Stanley and Linskens, 1974). Conditions with decreased oxygen during storage can positively affect pollen viability. Oryza sativa pollen grains can be stored and maintained its viability for 3 days at room temperature with high $\mathrm{RH}$ levels varying from 60 to 100\% (Saoji and Rewatkar, 2015).

Highest percent pollen viability $(41.84 \%)$ and germination $(29.51 \%)$ were recorded in pollen stored in amber glass at $-5^{\circ} \mathrm{C}$ after 24 hours storage. However, highest percent pollen viability after 48 hours was only 

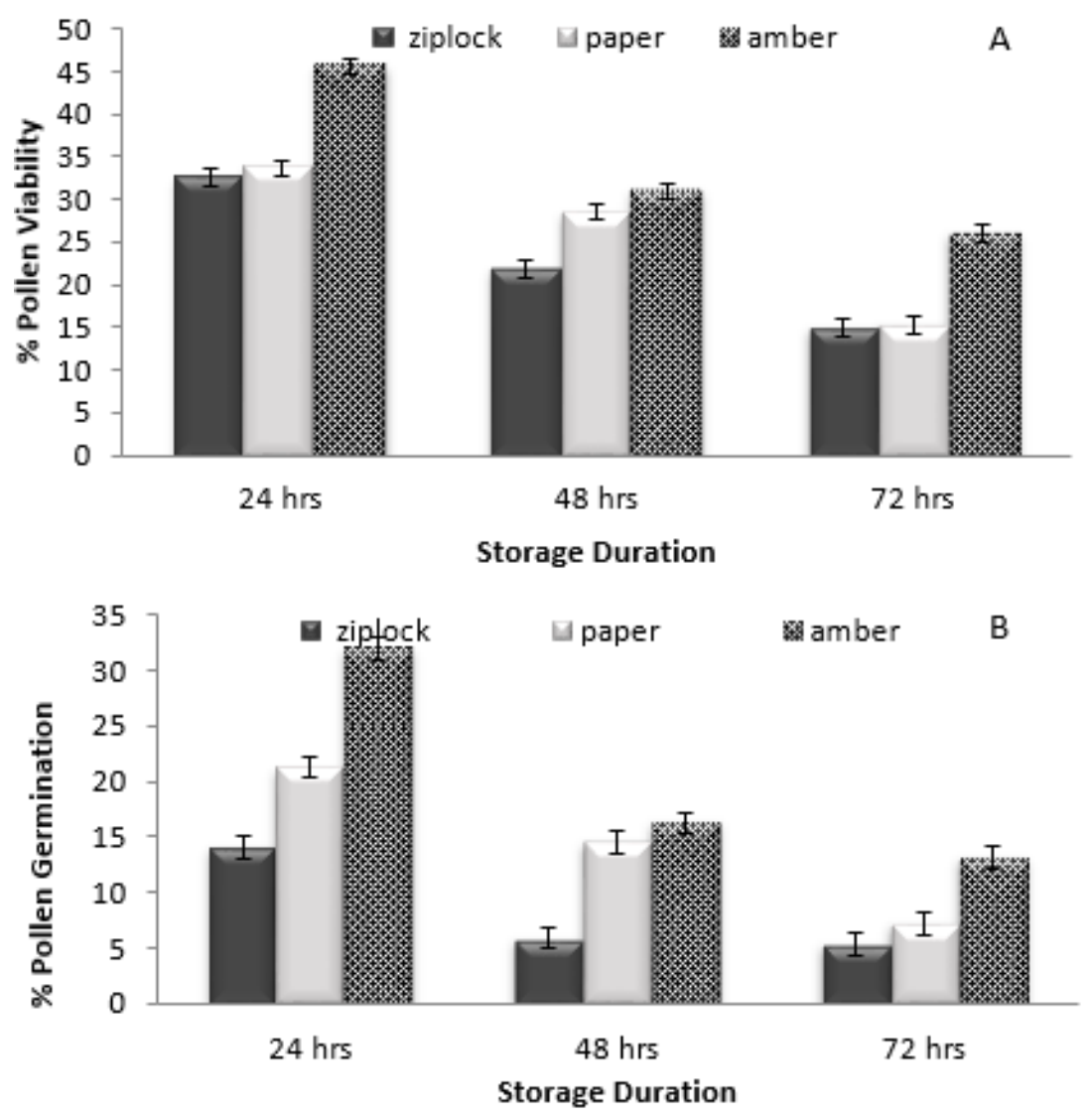

Figure 3. Pollen viability $(A)$ and germination rate $(B)$ at indicated treatments. Each data points represents the average of three replications. Error bars indicated standard error bars $(n=27)$

Table 5. Analysis of Variance of pollen viability, pollen germination under varying collection time and culture media used after $1 \mathrm{hr}$ storage before pollen evaluation.

\begin{tabular}{lccc}
\hline \multirow{2}{*}{ Source of Variation } & \multicolumn{3}{c}{ Mean Square } \\
\cline { 2 - 4 } & Viability & Germination & Pollen Tube Length \\
\hline Collection time & $2425.37^{*}$ & $779.01^{*}$ & $0.0019^{*}$ \\
Media & $12.93 \mathrm{~ns}$ & $73.65 \mathrm{~ns}$ & $0.0127^{*}$ \\
Collection time x Media & $199.37 \mathrm{~ns}$ & $53.30 \mathrm{~ns}$ & $0.0019^{*}$ \\
CV \% & 26.08 & 11.37 & 26.08 \\
\hline
\end{tabular}

Table 6. Analysis of variance of storage duration, storage materials and storage temperature and its effect on pollen viability and germination.

\begin{tabular}{lcc}
\hline \multirow{2}{*}{ Source of Variation } & \multicolumn{2}{c}{ Mean Square } \\
\cline { 2 - 3 } & Viability & Germination \\
\hline Storage Duration (A) & $2034.007 \mathrm{~ns}$ & $326.2803 \mathrm{~ns}$ \\
Storage Materials (B) & $283.0549 \mathrm{~ns}$ & $417.6475 \mathrm{~ns}$ \\
Storage Temperature (C) & $757.7474 \mathrm{~ns}$ & $465.8936 \mathrm{~ns}$ \\
A x B & $36.3374^{*}$ & $75.2427^{\star}$ \\
A x C & $10.9324^{\star *}$ & $4.8398^{\star *}$ \\
B x C & $5.9027^{\star *}$ & $0.6811^{\star *}$ \\
A x B x C & $5.7971^{* *}$ & $6.1544^{\star *}$ \\
CV \% & 20.07 & 13.54 \\
\hline
\end{tabular}

$30.97 \%$ or a decrease of $10.87 \%$ was noted from highest pollen viability after 24 hours. Percentage pollen viability when stored for 72 hours ranged from 6 to $18 \%$ while germinated pollen ranged between 5 to $15 \%$. Lowest percentage pollen viability (14.95\%) and germination (5.85) were observed using ziplock plastic at room temperature $\left(28^{\circ} \mathrm{C}\right)$ after 72 hour (Figure 3$)$. Analysis of variance showed that storage materials, storage temperatures and storage duration and its interaction to each other significantly affected pollen viability and germination (Table 6).

Rice pollen had maximum germination (58.38\%) and desirable tube length (289.65 um) after six days of storage at $80 \% \mathrm{RH}$ (Saoji and Rewatkar, 2015). Results of the present study was parallel to the study of Shivanna et al.
(1992) that pollen for short term storage required low temperature and low humidity. Other study on pollen storage used sealed containers such as vials, aluminum foil cups or gelatin capsules. Storage in desiccator with silica are among the recommended storage materials (Johri and Vasil 1961). Maintenance of pollen germination capacity highly depends on the conditions of storage. Low relative humidity $(\mathrm{RH})$, low temperature and optimal atmosphere surrounding the pollen prolong shelf-life (Stanley and Linskens, 1974).

\section{Summary and conclusion}

Pollen grains play significant role in rice development, as 
viable pollen is critical in efficient pollination and plant reproduction. Seed setting, the result of successful pollination, is greatly dependent in synchronized opening of both spikelets of TGMS parents (PRUPTG101 and TG101M) and in sufficient amount of male gametes deposited in tissues of female stigmas and style. With diverse background of individual TGMS parents, each dehisces at different time of the day, resulting in low percentage seed set in hybrid seed production of Mestiso 19. Results showed that highest percentage pollen viability and germination was achieved during anthesis collection.

Likewise, longest pollen tube growth was attained during anthesis collection. Pollen viability and germination decreased over time regardless of media used, but pollen grains grown in medium 2 maintained pollen viability even 1 hour after anthesis. Highest pollen viability and germination was achieved using amber glass stored at $5^{\circ} \mathrm{C}$. However, pollen decreased its viability and germination beyond 24 hours. To increase the chance of effective pollination in Mestiso 19, pollen grains must be collected at anthesis and stored immediately in amber glass under $-5^{\circ} \mathrm{C}$. Future studies can be done to develop standard protocol for rice pollen collection, processing and storage in TG101M. It will be interesting to do further research on loading collected pollen of TG101M after anthesis and even after 24 hour of storage to the stigma of PRUP TG101 and determine if percentage seed set will increase.

\section{CONFLICTS OF INTEREST}

We do not have any conflicts of interest.

\section{ACKNOWLEDGEMENTS}

The authors are thankful for Philippine Rice Research Institute for funding this study. Special thanks, likewise, was also credited to Ms. Fryne Krystal Jay Padron and Mr. Marcelino Maturillas for the data gathering.

\section{REFERENCES}

Barrow, J. R. (1983). Comparisons among pollen viability measurement methods in cotton. Crop Science, 23, 734-736.

Boavida, L. C., McCormick, S. 2007. Temperature as a determinant factor for increased and reproducible in vitro pollen germination in Arabidopsis thaliana. Plant Journal, 52 , 570-82.

Bolat, I., \& Pirlak, L. (1999). An investigation on pollen viability, germination and tube growth in some stone fruits. Turkish Journal of Agriculture and Forestry, 23(4), 383-388.

Buitink, J., Leprince, O., Hemminga, M. A., \& Hoekstra, F. A. (2000). The effects of moisture and temperature on the ageing kinetics of pollen: interpretation based on cytoplasmic mobility. Plant, Cell \& Environment, 23(9), 967-974.

Buitink, J., Walters-Vertucci, C., Hoekstra, F. A., \& Leprince, O. (1996). Calorimetric properties of dehydrating pollen (analysis of a desiccation-tolerant and an intolerant species). Plant Physiology, 111(1), 235-242

Chaudhury, R., Malik, S. K., \& Rajan, S. (2010). An improved pollen collection and crtopreservation method for highly recalcitrant tropical fruit species of mango (Mangifera indica $L$.) and litchi (Litchi chinensis Sonn.) CryoLetters, 31(3), 268-278.

Connor, K. F., \& Towill, L. E. (1993). Pollen-handling protocol and hydration/dehydration characteristics of pollen for application to long-term storage. Euphytica, 68(1-2), 77-84.

Craddock, J. H., Reed, S. M., Schlarbaum, S. E., \& Sauve, R. J. (2000). Storage of flowering dogwood (Cornus florida L.) pollen. HortScience, 35(1), 108-109.

Dafni, A., \& Firmage, D. (2000) Pollen viability and longevity: practical, ecological and evolutionary implications. In: Dafni A. Hesse M., Pacini E. (eds) Pollen and Pollination. Springer, Vienna. Pp. 113-132

Dutta, S. K., Srivastav, M., Chaudhary, R., Lal, K., Patil, P. Singh, S. K., \& Singh, A. K. (2013). Low temperature storage of mango (Mangifera indica L.) pollen. Scientia Horticulturae, 161, 193-197.
Firmage, D. H., \& Dafni, A. (2001). Field tests for pollen viability: a comparative approach. Acta Horticulturae, 561, 87-94.

Ganeshan, S., Rajasekharan, P. E., Shashikumar, S., \& Decruze, W. (2008). Cryopreservation of pollen In: Reed BM editor. Plant Cryopreservation: A Practical Guide. Springer, New York. Pp. 443-464.

Heslop-Harrison, J. S. (1992). Cytological techniques to assess pollen quality. In: Cresti M, Tiezzi A, editors. Sexual Plant Reproduction. Springer Verlag, Heidelberg. Pp. 41-48.

Hoekstra, F. A. (1986). Water content in relation to stress in pollen. In: Leopold AC, editor. Membranes, Metabolism and Dry Organisms. Cornell University Press, Ithaca, New York. Pp. 102-122

Johri, B., \& Vasil, I. K. (1961). Physiology of pollen. The Botanical Review, 27(3), 325-381.

Kakani, V. G., Reddy, K. R., Koti, S., Wallace, T. P., Prasad, P. V. V., Reddy, V. R., \& Zhao, D. (2005). Differences in in vitro pollen germination and pollen tube growth of cotton cultivars in response to high temperature. Annals of Botany, 96(1), 59-67.

Lee, Y. J., Yang, C. M., Chang, K. W., \& Shen, Y. (2011). Effects of nitrogen status on leaf anatomy, chlorophyll content and canopy reflectance of paddy rice. Botanical Studies, 52(3), 295-303.

Matsui, T., Omasa, K., \& Horie, T. (1999a). Mechanism of anther dehiscence in rice (Oryza sativa L.). Annals of Botany, 84(4), 501-506.

Matsui, T., Omasa, K., \& Horie, T. (1999b). Rapid swelling of pollen grains in response to floret opening unfolds anther locules in rice (Oryza sativa L.). Plant Production Science, 2(3), 196-199.

Rajasekharan, P. E., \& Ganeshan, S. S. (1994). Freeze preservation of rose pollen in liquid nitrogen: feasibility, viability and fertility status after long-term storage. Journal of horticultural science, 69(3), 565-569.

Roberts, E. H. (1961). The viability of rice seed in relation to temperature, moisture content, and gaseous environment. Annals of Botany, 25(3), 381-390.

Rodriguez-Enriquez, M. J., Mehdi, S., Dickinson, H. G., \& GrantDownton, R. T. (2013). A novel method for efficient in vitro germination and tube growth of Arabidopsis thaliana pollen. New Phytologist, 197(2), 668-679.

Saoji, A. A., \& Rewatkar, K. G. (2015). Studies on pollen storage at different temperature and humidity conditions in Oryza sativa L. International Journal of Researches in Biosciences, Agriculture and Technology, 304-305

Shivanna K. R., \& Rangaswamy N. S. (1992). Pollen Germination and Pollen Tube Growth in vitro. In: Pollen Biology. Springer, Berlin, Heidelberg. Pp. 5-37.

Shivanna K. R., \& Sawhney, V. K. (1997). Pollen Biotechnology for Crop Production and Improvement. Cambridge University Press, Cambridge. Pp. 13-84

Shivanna, K. R. (2003). Pollen Biology and Biotechnology. Science Publishers, Inc., USA, Pp. 181-182.

Shivanna, K. R., Linskens, H. F., \& Cresti, M. (1991). Pollen viability and pollen vigor. Theoretical and Applied Genetics, 81(1), 38-42.

Stanley, R. G., \& Linskens, H. F. (1974). Pollen. Springer-Verlag, Berlin Heidelberg New York. Pp. 56-88.

Steer, M. W., \& Steer, J. M. (1989). Pollen tube tip growth. New Phytol. III: 323-358.

Suy, T. B. (1979). Contribution of l'etude de la croissance des tubes polliniques chez Gossypium hirsutum L. en function des conditions du milieu. Coton et Fibres Tropicales, 34, 295-300.

Towill, L. E. (1985). Low temperature and freeze-/vacuum-drying preservation of pollen. In: Kartha KK, editor. Cryopreservation of Plant Cells and Organs. CRC Press, Boca Raton, Florida. Pp. 171-198.

Towill, L. E. (2004). Pollen storage as a conservation tool. In: Guerrant EO, Havens K, Maunder M, editors. Ex Situ Plant Conservation: Supporting Species Survival in the Wild. Island Press, Washington DC. Pp.180-188.

Tuinstra, M. R., Wedel, J. (2000). Estimation of pollen viability in grain sorghum. Crop Science, 40, 968-970.

van Bilsen, D. G., Hoekstra, F. A., Crowe, L. M., \& Crowe, J. H. (1994). Altered phase behavior in membranes of aging dry pollen may cause imbibitional leakage. Plant Physiology, 104(4), 1193-1199.

Van Der Walt, I. D., \& Littlejohn, G. M. (1996). Storage and viability testing of Protea pollen. Journal of the American Society for Horticultural Science, 121(5), 804-809.

Wang, H., \& Jiang, L. (2011). Transient expression and analysis of fluorescent reporter proteins in plant pollen tubes. Nature Protocols, 6(4), 419. 